\title{
DEVELOPMENT AND VALIDATION OF INSTRUMENT TO MEASURE THE CHARACTERISTICS OF A HEALTHY ROLE-MODEL IN MEDICAL SCHOOL
}

\author{
Michael Andreas Leman ${ }^{1 *}$, Mora Claramita², Gandes Retno Rahayu² \\ ${ }^{1}$ School of Dentistry, Faculty of Medicine, Universitas Sam Ratulangi, Manado - INDONESIA \\ ${ }^{2}$ Faculty of Medicine, Public Health and Nursing, Universitas Gadjah Mada, Yogyakarta - INDONESIA \\ Submitted: 17 Nov 2020; Final Revision from Authors: 14 Mar 2021; Accepted: 15 Mar 2021
}

\begin{abstract}
Background: A medical teacher as a healthy role-model has a critical role in supporting health promotion effectiveness in medical school. However, an instrument to measure the characteristics of the medical teacher as a healthy role-models is unavailable. This study aimed to develop and validate a questionnaire to evaluate these characteristics by analyzing a model from previous grounded theory.
\end{abstract}

Methods: A total of 442 medical teachers at the Faculty of Medicine, Public Health, and Nursing, Universitas Gadjah Mada, Yogyakarta, were invited to participate. We used hierarchical component models (HCMs) to develop our path model. A partial least squares structural equation modeling (PLS-SEM) were then used to analyze this model.

Results: Twenty-six items from seven constructs supports our model. The construct of socially healthy (SH) has the most substantial effect on constructing healthy people's characteristics $(H)$. The constructs of healthy role-models (HRM) in medical schools are mainly influenced by healthy people characteristic $(H)$.

Conclusion: A questionnaire with 26 items grouped in these seven constructs showed good reliability and validity. Seven constructs have relevance to the characteristics of a healthy role-model in the medical school model.

Keywords: role-model, PLS-SEM, medical schools

\section{PRACTICE POINTS}

- Seven constructs were relevant to the characteristics of a healthy role-model in the medical school model.

- Healthy person characteristics have a significant contribution to the characteristics of a healthy rolemodel in medical school.

- PLS-SEM is one of the compromising methods that can be used to analyze a model in medical education research.

*corresponding author, contact: micpatlem1982@unsrat.ac.id 


\section{INTRODUCTION}

The medical school is one context of health promotion concerned by the World Health Organization (WHO) since 1995. By implementing health promotion, a medical school should provide a safe environment and culture that enables people to increase control and improve their health. ${ }^{1}$ The health-promoting University (HPU) is an initiative that can be used by the medical school to fulfill this goal. There were six main focuses of implementing HPU; one is to produce a good role model of health promotion. ${ }^{1,2}$ From our previous study, ${ }^{3}$ we described it as a healthy role-model. In that study, we conducted a grounded theory to define healthy role-models characteristics in medical school because no theoritical concept was found to explain this construct.

The importance to implement HPU is also strengthened by the clause "I will attend to my own health, well-being, and abilities, in order to provide care of the highest standard" on modern-day physician pledge adopted by the World Medical Association. ${ }^{4}$ Faculty staff and students are asked not only healthy for themselves but also expected to act as agents of change in society through the role of healthy role models. ${ }^{1}$ In medical school, the medical teacher is a critical component of the educational environment. ${ }^{5}$ In many publications, the effectiveness of teacher's role-modeling in teaching professional behaviors to medical students has been proved as an effective learning method. ${ }^{6-10}$ This effectiveness might also apply to the development of healthy physician characteristics.

However, the characteristics of the medical teacher as a healthy role model in medical school are difficult to evaluate because of the absence of an instrument to evaluate. Therefore in this study, we develop and validate an instrument to measure these characteristics by using the result of our previous grounded theory.

\section{METHODS}

\section{Study context}

This research was conducted at the Faculty of Medicine, Public Health, and Nursing, Universitas Gadjah Mada, Yogyakarta (FK-KMK UGM),
Yogyakarta. A total of 546 medical teachers at the FK-KMK UGM as the study population. One hundred four medical teachers were eliminated because some of them were retired or did not have complete contact information (i.e., an electronic mail (e-mail) or phone number) obtained from the Human Resources Division Unit of FK-KMK UGM. A total of 442 medical teachers from 32 departments were invited to complete a questionnaire to measure the characteristics of a healthy role model of medical school in this study.

\section{Development of items}

Forty items from previously grounded theory ${ }^{3}$ on a healthy role-model in medical schools and one item from a literature review on healthy people's characteristics ${ }^{11}$ were included as pool item inventory in this study. All items were then written by using the guidelines on developing questionnaires from Artnino et al. ${ }^{12}$ We chose not to follow a recommendation from these guidelines, e.g., by writing the item into statements rather than questions based on our concern that these items draw characteristics that might be irritated to our respondents. We used a four-point Likert scale as responses ranging from not very appropriate to very appropriate. A four-point Likert scale was used to minimize the possibility that a respondent might choose the middle response.

\section{Conducting expert validation}

We selected a panel of experts by following these criteria: having a background in the health profession area, working as a teacher in one of health education schools, and having interested in topics related to role-models, role-modeling, or health promotion and education. Twelve experts met our criteria, ten experts from Indonesia, and two experts from overseas. All items were then translated into English. Two experts who have a Health Profession Education background were helped to check all translated items if the item has a different meaning from original Indonesia items. Revisions were then made based on their review.

Six of 12 experts participated in this process. All experts come from Indonesia. To increase the number of experts on this process, we also invited 
40 respondents from our previous grounded theory. All of these respondents met the same criteria as the previous experts. Fifteen of 40 respondents fulfilled our invitation. They come from Indonesia, Australia, the Netherlands, the United Kingdom, and Canada. In the final step, we used 21 responses from 6 experts and 15 respondents.

All of their responses were recorded as expert validation. We used a content validity ratio (CVR) by Lawshe. ${ }^{13}$ The minimum CVR value is 0.42 ( $\mathrm{p}$ $<0.05$ ) based on 21 expert responses. Fifteen items were eliminated since those items did not meet the minimum CVR value. All remaining items were corrected based on the review from our experts.

In this step, all experts were given 14 days to give their review to our items. We also gave 20 additional days to facilitate the expert who did not send their review yet. All invitations were sent by e-mail or WhatsApp. We used a google form to facilitate our expert validation process. We added a blank box below each item to facilitate the expert's review of that item. We also added a blank box at the end of the review to facilitate the experts in giving their general comments about our items and questionnaire.

\section{Cognitive interview}

This step aims to test the questionnaire. It is conducted based on psychological theory that there are four cognitive processes (comprehension, retrieval of appropriate information from long-term memory, judgment based comprehension, and selection of response) that occur when a person responds to a survey study. ${ }^{14}$ By doing this process, the researchers can assess if the respondent does not have a problem in interpreting each item correctly. ${ }^{15,16}$ The review that obtained from this process can be used to identify misinterpretations of each item or the response's scale which made by respondent. ${ }^{16}$

There are two techniques commonly used in conducting cognitive interviews, i.e., think-aloud technique and verbal probing. In this study, we used immediate retrospective probing, a type of verbal probing technique, which developed by Watt., ${ }^{17}$ which has "a breaking point" in the questionnaire. When the respondent reaches that breaking point, the interviewer gives several questions that relate to the items. This method allows the interviewer to explore the insight of respondents without disturbing their concentration in answering the items. This method can also minimize recall bias and hindsight effects.

In general, cognitive interviews are conducted faceto-face interviews. However, in this study, we used phone communication because of the different locations between the interviewer and respondents. We used six exploring questions adapted from Willis and Artino ${ }^{18}$ in this step: 1 ) What do you think when you are asked about (item)?; 2) What does the word (a word in the item) mean to you? 3) What information do you need so you know that that item appropriate to you?; 4) Are you sure about the answer you gave for the item?; 5) Do you find it difficult to answer (item)?; and, 6) Are the scale response is appropriate to the item? These six questions represent the four cognitive processes according to psychological theory. Each item was then further explored with 'What' and 'Why' words. We made 12 sections for our cognitive interview. Each section consists of one to six items that correlated with each other.

We conducted eight cognitive interview sessions. All of our respondents were medical teachers from medical schools in Indonesia. Six medical teachers work at the medical schools in the West region of Indonesia and two medical teachers from medical schools in the East region of Indonesia. We conducted an item revision based on our respondent review and used in the next cognitive review session with the different respondent. We also asked our next respondent to comment on the item before and after it was revised. Each cognitive interview lasts for approximately 25 to 80 minutes.

In this process, we also checked the readability of our questionnaire. We asked our respondents to write the amount of time they used to complete the questionnaire. An average time to complete the questionnaire was 30 minutes. The overall form of the questionnaire was also evaluated. We then made corrections to our questionnaire based on their reviews. We developed 35 items from the 26 remaining items based on the review of our respondents. One of the 35 items, i.e., PH3 ("I can carry out my daily activity without limitation caused by suffering a certain disease") in the PH construct, 
is a conditional item. This item is responded if the respondent chooses a specific response in the previous question. We consulted this item development and revision with the two experts in medical education area. They help us to evaluate if the 35 items have the same meaning as 26 items before. They also help to confirm if the questionnaire is ready to use in the data collection.

\section{Data collection}

We sent an invitation letter to medical teachers in each department after the head of a departmentapproved it. We followed a particular policy of each department when sent this questionnaire link. This data collection was conducted from January 2019 to January 2020.

\section{Model analysis}

Our model is a higher-order model or hierarchical component models (HCMs) in the context of PLSSEM, where the lower-order component is reflective. This model has one second-order construct, three exogenous latent variables, and one endogenous latent variable, with a total of 35 items. A secondorder construct is a healthy person $(\mathrm{H})$. It has four first-order constructs, i.e., physically healthy $(\mathrm{PH})$ with three reflective items, mentally healthy $(\mathrm{MH})$ with 12 reflective items, socially healthy $(\mathrm{SH})$ with seven reflective items, spiritually healthy $(\mathrm{SpH})$ with two reflective items. The exogenous latent variables, i.e., internalized healthy behaviors (IHB) has six reflective items, willingness to promote healthy lifestyles (WTP) has two reflective items, and lifelong learner (LLL) has three reflective items. The endogenous latent variable is a healthy role model (HRM). We use higher-order models (HCM) because its advantages: helps to reduce the number of path model relationships, thus providing a more concise model to describe the relationship between several independent variables (first-order construct, secondorder construct, and exogenous latent variables) and dependent variable (endogenous latent variable) in the model path; minimizing collinearity issues caused by strong correlations between lower-order components (first and second-order construct) in this model that can interfere discriminant validity. ${ }^{19}$
Figure 1 shows this path model.

We used the Partial Least Squares Structural Equation Modeling (PLS-SEM) to analyze our model. PLS-SEM is an analytical technique that prioritizes repetition; thus, it maximizes the variance that occurs in endogenous latent variables. ${ }^{20}$ The researchers who used PLS-SEM in the model analysis is intended for exploratory research. A PLS-SEM is suitable for exploratory research, especially to explain the relationship of variables in the model..$^{21,22}$ In this study, we used PLS-SEM to explore the characteristics of a healthy role-model in the medical school model that is not explained yet in anywhere topics of publication. Therefore, no literature could be used to explain the relationship between the construct, which is related to this model. We used a PLS-SEM Professional Ver. 3.3.0 in this study. We carried out model analysis after obtaining data from the survey.

The test of data normality should be performed first before conducting the model analysis. Data has a normal distribution if skewness and kurtosis are between values -1 and $+1{ }^{23}$ To analyze the model, the researcher must conduct the assessment of the measurement model and the structural model. Because this model is a higher-order model or hierarchical component models (HCMs) in the PLSSEM context, the assessment of measurement model (the relationship between items and constructs) for higher-order components must be carried out before the assessment of the structural model is conducted. The assessment of the measurement model helps researchers to evaluate how well and appropriate their developed model with the reality in the field (based on data obtained from data collection). Because the lower-order constructs are reflective (reflective measurement model), we considered evaluating some criteria. First, internal consistency reliability by evaluating Cronbach's alpha and composite reliability value. The value of at least 0.6 of it is considered to be quite reliable, especially for exploratory research. Second, convergent validity is assessed by evaluating the outer loading value of the item and the average variance extracted (AVE) value of the construct. The outer loading of the item should be greater than 0.708 , and the value of AVE 


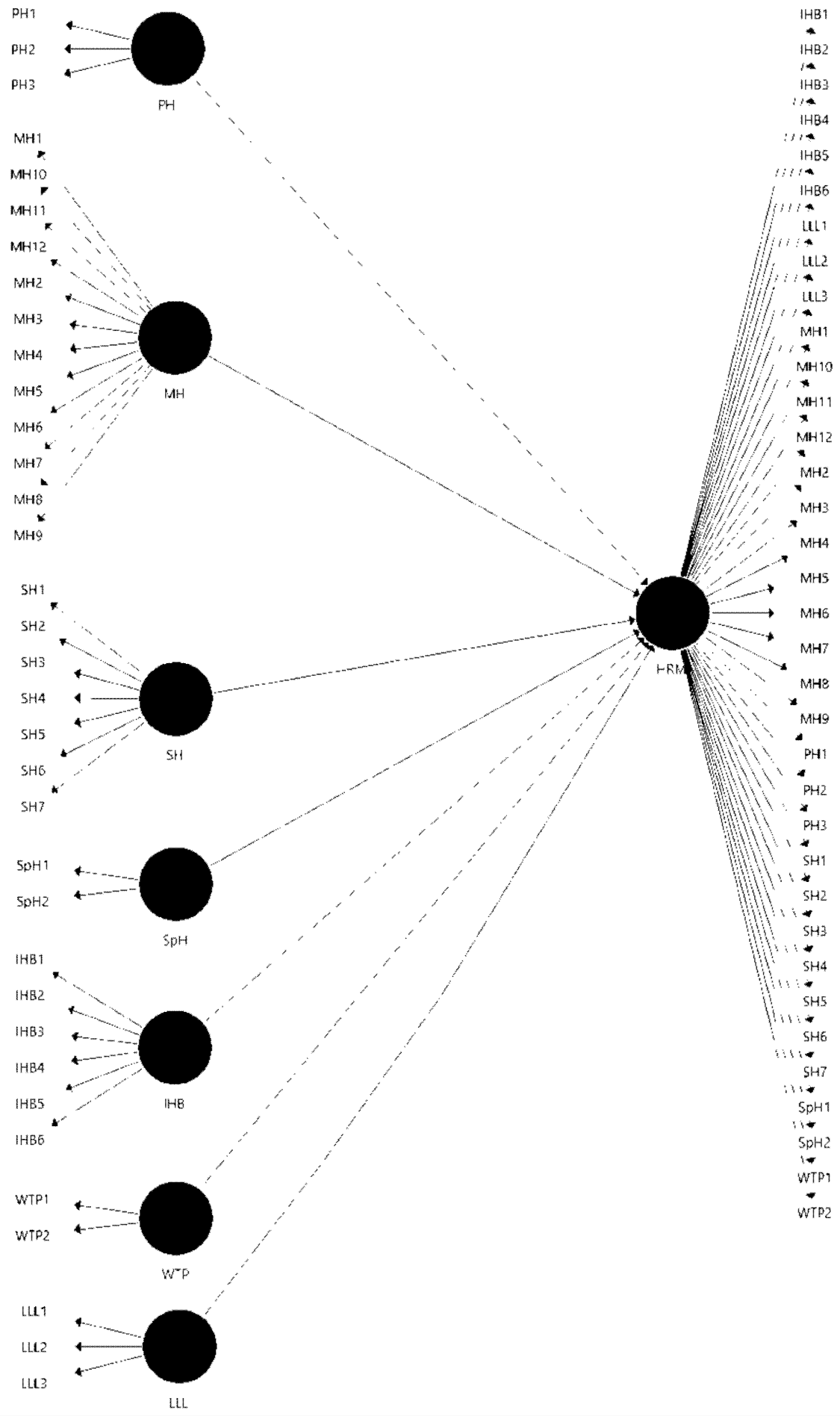

Figure 1. Path model

should higher than 0.5 . Third, discriminant validity is assessed by comparing the cross-loading of an item in the construct and its cross-loading in other constructs. One item must have the highest crossloading on its construct. In PLS-SEM, all constructs must correlate with the heterotrait-monotrait ratio (HTMT) that does not include 1.0. If all criteria above were met, the model shows good reliability and validity; thus, the assessment of the structural model could be assessed. 
In assessing the structural model, some values need to be considered, i.e., construct's tolerance (VIF), coefficient of determination $\left(R^{2}\right)$, the effect size $\left(f^{2}\right)$, and predictive relevance $\left(\mathrm{Q}^{2}\right)$ value. A VIF value should be higher than 0.2 but lower than 5.0 , or the construct is considered to be eliminated or combined with other constructs to treat collinearity problems (the independent variable explains the same variance as the dependent variable). $\mathrm{R}^{2}$ represents the amount of variance in the endogenous latent variable (dependent variable) that can be explained by all the independent variables linked to it. It stated that $R^{2}=0.75$ is large, $R^{2}=0.5$ is medium, and $R^{2}=0.25$ is small. The value of $f^{2}$ represents the amount of contribution of the independent variable to the dependent variable. The value of $\mathrm{f}^{2}$ $=0.35$ is large, $\mathrm{f}^{2}=0.15$ is medium, and $\mathrm{f}^{2}=0.02$ is small. $Q^{2}$ value, which higher than zero, indicates that the model is fitted with the data in the field. It explains that item can represent their latent variable, and all exogenous latent variables represent the endogenous latent variable. It also explains that the exogenous latent variables have a predictive relevance to the endogenous latent variable they represented. Therefore, the model fits with all of its exogenous latent variables.

This study was approved by The Medical and Health Research Ethics Committee Faculty of Medicine, Public Health and Nursing, Universitas Gadjah Mada, Indonesia, under their file number 0946 and 1217.

\section{RESULTS AND DISCUSSION}

Seventy-nine of 442 medical teachers at the FK-KMK UGM participated in this study. Even though this study's response rate is relatively low (17.87\%), it met the minimum sample size of PLS-SEM to analyze this model.

\section{Data distribution}

A conditional item (PH3) was excluded from test normality because it could not be assessed due to missing values issues. The skewness of 15 items and kurtosis of 19 items in this model were not in a normal distribution. Skewness and kurtosis also provided a different data distribution on several items. However, we continued to analyze this model since there is no requirement that data must be normally distributed when conducting PLS-SEM.

\section{Assessing the measurement model \\ Internal consistency reliability}

The Cronbach's alpha of all constructs is satisfactory, except the PH construct that has a value below 0.6. In this study, we did not exclude the $\mathrm{PH}$ construct, which did not meet the minimum Cronbach's alpha value for exploratory research. We prefer to consider the composite reliability instead of Cronbach's alpha value for this construct due to the limitation of Cronbach's alpha that generally tends to underestimate the internal consistency reliability because it is sensitive to the number of items the scale. We also considered that PLS-SEM prioritizes the reliability of each item and not all items in the scale were assessed using Cronbach's alpha. ${ }^{20}$

All constructs have composite reliability values above 0.6. All constructs did not have Cronbach's alpha value above 0.95 . It showed that no items measure the same thing in this model.

\section{Convergent validity}

Two items (PH1 and IHB1) have an outer loading value below 0.4. Therefore, these two items were eliminated. An item with very low outer loading (below 0.4) should, however, always be eliminated from the construct. ${ }^{23}$ Seven items in two constructs (MH3, MH4, MH5, MH10, MH11, MH12, and IHB2), which have weaker outer loading (below 0.708), were also eliminated. We eliminated those items to increase the AVE value of two constructs; thus, they met the minimum value. However, the researchers need to be careful when eliminating items with outer loading value below 0.708 and examine the effect of item removal on the composite reliability, especially on a newly developed construct. The elimination of items should be considered only when deleting the indicator leads to an increase in composite reliability. ${ }^{24}$

In this study, the composite reliability of these two constructs was also increased when those items were 
eliminated. The elimination of those items not affected the content validity of those constructs since our model is a reflective measurement model. Table 1 shows the outer loading values of 26 items in the model. Eight items (MH6, MH8, MH9, SH1, SH3,
SH4, IHB4, and IHB5) still had outer loading values below 0.708 , but we did not eliminate all of these items since AVE value of their construct has above 0.5. From this result, we confirmed that the model had achieved an excellent convergent validity.

Table 1 . The outer loading value of 26 items in the model

\begin{tabular}{|c|c|c|c|c|c|c|c|}
\hline \multirow{2}{*}{ Item } & \multicolumn{7}{|c|}{ Construct } \\
\hline & PH & MH & SH & $\mathrm{SpH}$ & IHB & WTP & LLL \\
\hline PH2 & 0,819 & & & & & & \\
\hline PH3 & 0,720 & & & & & & \\
\hline MH1 & & 0,715 & & & & & \\
\hline MH2 & & 0,763 & & & & & \\
\hline MH6 & & $0,686^{*}$ & & & & & \\
\hline MH7 & & 0,733 & & & & & \\
\hline MH8 & & $0,698^{*}$ & & & & & \\
\hline MH9 & & $0,644^{*}$ & & & & & \\
\hline SH1 & & & $0,649^{*}$ & & & & \\
\hline $\mathrm{SH} 2$ & & & 0,774 & & & & \\
\hline SH3 & & & $0,694^{*}$ & & & & \\
\hline $\mathrm{SH} 4$ & & & $0,681^{*}$ & & & & \\
\hline SH5 & & & 0,822 & & & & \\
\hline SH6 & & & 0,873 & & & & \\
\hline $\mathrm{SH} 7$ & & & 0,744 & & & & \\
\hline SpH1 & & & & 0,841 & & & \\
\hline $\mathrm{SpH} 2$ & & & & 0,916 & & & \\
\hline IHB3 & & & & & 0,804 & & \\
\hline IHB4 & & & & & $0,691^{*}$ & & \\
\hline IHB5 & & & & & $0,661^{*}$ & & \\
\hline IHB6 & & & & & 0,777 & & \\
\hline WTP1 & & & & & & 0,908 & \\
\hline WTP2 & & & & & & 0,904 & \\
\hline LLL1 & & & & & & & 0,763 \\
\hline LLL2 & & & & & & & 0,752 \\
\hline LLL3 & & & & & & & 0,818 \\
\hline
\end{tabular}

*Item with outer loading $<0.708$

PH1 (I haveideal body weight and height)

PH2 (I havegood stamina)

PH3 (I can do my regular activity without limitation even though having a chronic disease)

MH1 (I am happy with my life)

MH2 (I appreciate the life I am living)

MH3 (I am an honest person)

MH4 (I practice a routine self-reflection)

MH5 (I have excellent emotional management)

MH6 (I have excellent coping skills)

MH7 (I am positive thinkers)

MH8 (I have proper sleep during rest time)

MH9 (I have good time management skills)

MH10 (I know my self-limitations)

MH11 (I can make priorities of my work)

MH12 (I have a work ethic in doing my job)

SH1 (I always respect others) 
SH2 (I practice empathy, compassion, and altruism)

$\mathrm{SH} 3$ (I give constructive feedback to others)

SH4 (I create a safe environment for others)

SH5 (I make friends without discriminating)

SH6 (I am obedient to norms)

$\mathrm{SH} 7$ (I can work as a team)

Sp1 (I have an excellent vertical relationship with God in their beliefs, e.g., having prayer time regularly)

Sp2 (I am entrusting my life to God)

IHB1 (I conduct regular physical activity)

IHB2 (I eat healthy food)

IHB3 (I realized that I am vulnerable to get an infection. Thus, I follow a standardized health protection protocol when treating the patients)

IHB 4 (I have a regular health check)

IHB5 (I have self-regulation to prevent the adoption of unhealthy behavior)

IHB6 (I usually consult a medical professional when I feel any discomfort in my body)

LLL1 (I attend continuing education regularly)

LLL2 (I assess health information I received critically)

LLL3 (I conduct health research that benefits their environment)

WTP1 (I commit to inviting other people in practicing healthy behavior, e.g., by sharing my experiences about conducting healthy behavior) WTP2 (I participate actively in health programs that
conducting in the environment)

\section{Discriminant validity}

All items have the highest cross-loading value in its construct. The HTMT values for all constructs are below 1. Based on these two criteria, a model has proven a good discriminant validity. When using PLS-SEM, the researcher should consider the HTMT values to complement the cross-loading of the item. The HTMT approach would estimate the real correlation between the two constructs if they were perfectly reliable. ${ }^{25}$ Table 2 summarizes the assessment of the measurement model. From this result, we stated that the model with 26 items proved to have excellent reliability and validity. Therefore, we could continue to assess the structural model.

Table 2. The summary of measurement model assessment

\begin{tabular}{|c|c|c|c|c|c|}
\hline \multirow{2}{*}{ Construct } & \multirow{2}{*}{ Item } & \multicolumn{2}{|c|}{ Internal Consistency Reliability } & \multirow{2}{*}{$\begin{array}{c}\begin{array}{c}\text { Convergent } \\
\text { validity }\end{array} \\
\text { AVE }\end{array}$} & \multirow{2}{*}{$\begin{array}{c}\begin{array}{c}\text { Discriminant } \\
\text { validity }\end{array} \\
\text { HTMT < } 1\end{array}$} \\
\hline & & $\begin{array}{l}\text { Cronbach's } \\
\text { alpha }\end{array}$ & $\begin{array}{l}\text { Composite } \\
\text { reliability }\end{array}$ & & \\
\hline $\mathrm{PH}$ & $\begin{array}{l}\mathrm{PH} 2 \\
\mathrm{PH} 3\end{array}$ & $0,322^{*}$ & 0,745 & 0,595 & Ya \\
\hline $\mathrm{MH}$ & $\begin{array}{l}\text { MH1 } \\
\text { MH2 } \\
\text { MH6 } \\
\text { MH7 } \\
\text { MH8 } \\
\text { MH9 }\end{array}$ & 0,802 & 0,857 & 0,501 & Ya \\
\hline $\mathrm{SH}$ & $\begin{array}{l}\text { SH1 } \\
\text { SH2 } \\
\text { SH3 } \\
\text { SH4 } \\
\text { SH5 } \\
\text { SH6 } \\
\text { SH7 }\end{array}$ & 0,869 & 0,900 & 0,565 & Ya \\
\hline $\mathrm{SpH}$ & $\begin{array}{l}\mathrm{SpH} 1 \\
\mathrm{SpH} 2\end{array}$ & 0,711 & 0,871 & 0,773 & Ya \\
\hline IHB & $\begin{array}{l}\text { IHB3 } \\
\text { IHB4 } \\
\text { IHB5 } \\
\text { IHB6 }\end{array}$ & 0,715 & 0,824 & 0,541 & Ya \\
\hline
\end{tabular}




\begin{tabular}{|c|c|c|c|c|c|}
\hline \multirow{2}{*}{ Construct } & \multirow{2}{*}{ Item } & \multicolumn{2}{|c|}{ Internal Consistency Reliability } & \multirow{2}{*}{$\begin{array}{c}\begin{array}{c}\text { Convergent } \\
\text { validity }\end{array} \\
\text { AVE }\end{array}$} & \multirow{2}{*}{$\begin{array}{c}\text { Discriminant } \\
\text { validity }\end{array}$} \\
\hline & & $\begin{array}{c}\text { Cronbach's } \\
\text { alpha }\end{array}$ & $\begin{array}{l}\text { Composite } \\
\text { reliability }\end{array}$ & & \\
\hline WTP & $\begin{array}{l}\text { WTP1 } \\
\text { WTP2 }\end{array}$ & 0,782 & 0,902 & 0,821 & Ya \\
\hline LLL & $\begin{array}{l}\text { LLL1 } \\
\text { LLL2 } \\
\text { LLL3 }\end{array}$ & 0,677 & 0,821 & 0,606 & Ya \\
\hline
\end{tabular}

* Cronbach's alpha below 0.6

\section{Assessing structural model}

Firstly, we checked collinearity issues by examining the VIF values of all constructs. All constructs have a VIF value above 0.2 and below 5.0, which indicated that there are no collinearity problems in the structural model. Therefore, no construct needs to be eliminated or merged on this model.

Next, we evaluated the $\mathrm{R}^{2}$ value of endogenous latent variables ( $\mathrm{H}$ and $\mathrm{HRM}$ ). The $\mathrm{R}^{2}$ value of $\mathrm{H}$ and HRM constructs is equal to 1 . It could happen in the HCM model, where all items in the lower-order components were used to identify the higher-order component. It caused the variance in the higher-order component has been fully explained by the lowerorder component. All items in the $\mathrm{PH}, \mathrm{MH}, \mathrm{SH}$, and $\mathrm{SpH}$ construct in this model were used to identify the $\mathrm{H}$ construct and all items in the $\mathrm{PH}, \mathrm{MH}, \mathrm{SH}$, SpH, WTP, IHB, and LLL were used to identify the HRM construct. Becker et al. ${ }^{26}$ suggest the researcher should use the extended repeated indicator approach, a modification of the repeated indicator approach, in treating this problem. However, the results of the measurement of $\mathrm{R}^{2}$ in the HRM construct were still close to 1(0.991) after we used the extended repeated indicator approach. Therefore, we also use a twostage approach to complement the assessment results of the extended repeated indicator approach. This approach was used by several considerations: 1) the number of items in the lower-order component is not equal; thus it could lead bias in loading value of lower-order component when we used the repeated indicator approach; ${ }^{27,28}$ and, 2) because the lowerorder construct has explained all the variances in the higher-order construct $\left(\mathrm{R}^{2}=1\right)$; thus it is recommended to use the two-stage approach. ${ }^{27} \mathrm{We}$ ran bootstrapping on a model with 5000 subsamples (no sign changes) to assess the significance and relevance of the relationship between first-order components and second-order components. Table 3 shows the results of the structural model assessment by using these two approaches. 
Tabel 3. The structural measurement model assessment

\begin{tabular}{|c|c|c|c|c|c|c|}
\hline \multirow[b]{2}{*}{ Relationship } & \multicolumn{3}{|c|}{ Extended repeated indicator approach } & \multicolumn{3}{|c|}{ Two-stage approach } \\
\hline & Path coefficient & T values & $\begin{array}{l}P \text { values } \\
(p<0,05)\end{array}$ & Path coefficient & $\mathrm{T}$ values & $\begin{array}{l}\text { P values } \\
(p<0,05)\end{array}$ \\
\hline $\mathrm{PH} \rightarrow \mathrm{H}$ & $\begin{array}{c}0,073^{*} \\
(0,023 ; 0,121)\end{array}$ & 2,921 & Yes & $\begin{array}{c}0,071 \\
(0,025 ; 0,119)\end{array}$ & 3,011 & Yes \\
\hline $\mathrm{MH} \rightarrow \mathrm{H}$ & $\begin{array}{c}0,407^{*} \\
(0,348 ; 0,459)\end{array}$ & 14,639 & Yes & $\begin{array}{c}0,411 \\
(0,354 ; 0,464)\end{array}$ & 15,041 & Yes \\
\hline $\mathrm{SH} \rightarrow \mathrm{H}$ & $\begin{array}{c}0,549^{*} \\
(0,478 ; 0,623)\end{array}$ & 14,965 & Yes & $\begin{array}{c}0,546 \\
(0,477 ; 0,612)\end{array}$ & 16,128 & Yes \\
\hline $\mathrm{SpH}_{-} \rightarrow \mathrm{H}$ & $\begin{array}{c}0,193^{*} \\
(0,158 ; 0,236)\end{array}$ & 9,656 & Yes & $\begin{array}{c}0,189 \\
(0,158 ; 0,236)\end{array}$ & 9,458 & Yes \\
\hline $\mathrm{H} \rightarrow \mathrm{HRM}$ & $\begin{array}{c}0,538 \\
(0,456 ; 0,611)\end{array}$ & 13,599 & Yes & $\begin{array}{c}0,571 \\
(0,517 ; 0,628)\end{array}$ & 20,087 & Yes \\
\hline $\mathrm{IHB} \rightarrow \mathrm{HRM}$ & $\begin{array}{c}0,239 \\
(0,189 ; 0,306)\end{array}$ & 8,029 & Yes & $\begin{array}{c}0,208 \\
(0,184 ; 0,234)\end{array}$ & 16,068 & Yes \\
\hline $\mathrm{WTP} \rightarrow \mathrm{HRM}$ & $\begin{array}{c}0,193 \\
(0,143 ; 0,238)\end{array}$ & 7,953 & Yes & $\begin{array}{c}0,187 \\
(0,143 ; 0,222)\end{array}$ & 9,473 & Yes \\
\hline $\mathrm{LLL} \rightarrow \mathrm{HRM}$ & $\begin{array}{c}0,201 \\
(0,160 ; 0,241)\end{array}$ & 9,668 & Yes & $\begin{array}{c}0,207 \\
(0,174 ; 0,237)\end{array}$ & 13,257 & Yes \\
\hline $\mathrm{R}^{2} \mathrm{H}$ & 1 & & & 1 & & \\
\hline $\mathrm{R}^{2} \mathrm{HRM}$ & 0,991 & & & 0,991 & & \\
\hline$Q^{2} \mathrm{H}$ & 0,350 & & & 0,349 & & \\
\hline $\mathrm{Q}^{2} \mathrm{HRM}$ & 0,328 & & & 0,509 & & \\
\hline
\end{tabular}

Notes: number in brackets display the $95 \%$ bias-corrected percentile confidence intervals derived from bootstrapping with 5000 subsample (no sign changes); *Total effect

Based on the result of the table above, a $\mathrm{PH}, \mathrm{MH}, \mathrm{SH}$, and $\mathrm{SpH}$ construct have a significant total effect $(\mathrm{p}$ $<0.05$ ) on the $\mathrm{H}$ construct. The $\mathrm{SH}$ construct has the most potent total effect (0.549) on the H construct, followed by the construct $\mathrm{MH}$ (0.407), $\mathrm{SpH}$ (0.193), and $\mathrm{PH}(0.073)$. This shows that the characteristics of socially healthy $(\mathrm{SH})$ and mental healthy $(\mathrm{MH})$ have a major effect on the characteristics of healthy people $(\mathrm{H})$ rather than physically healthy $(\mathrm{PH})$ and spiritually $(\mathrm{SpH})$. Construct $\mathrm{H}$ has the strongest effect on the HRM construct (0.538) compared to IHB (0.239), LLL (0.201), and WTP (0.193). It shows that the characteristics of healthy people have a significant effect on the characteristics of healthy role models in medical school compared to internalized healthy behavior, willingness to promote healthy lifestyles and life-long learners' characteristics. However, all exogenous variables (H, IHB, LLL, and WTP) have an effect size value above 0.02 to endogenous variables (HRM). It shows that the characteristics of healthy people, internalized healthy behavior, willingness to promote healthy lifestyles, and life-long learners influence the characteristics of a healthy role model in medical schools. The $\mathrm{Q}^{2}$ value of endogenous construct ( $\mathrm{H}$ and HRM) are above $\mathrm{O}$. It shows that the first-order construct $(\mathrm{PH}, \mathrm{SH}, \mathrm{MH}$, and $\mathrm{SpH})$ has predictive relevance to the $\mathrm{H}$ construct. The exogenous construct (H, IHB, WTP, and LLL) also has a predictive relevance to the HRM construct. It proved that all seven constructs with 26 items fit this model.

In this study, we consider the limitation of our study: 1) sample size is quite small that might interfere the data distribution, Cronbach's alpha, and produce 
a weak outer loading value of some items; 2) three constructs (PH, SpH, WTP) in this model is considered inadequate since it has less than three items. Therefore, further study is needed to conduct more sample sizes; thus, it can increase the number of studies in order to provide more evidence to validate this model.

\section{CONCLUSION}

All seven constructs, i.e., physically, socially, mentally, spiritually health, internalized healthy behavior, and willingness to promote healthy lifestyles, a life-long learner fit the characteristics of a healthy role-model in the medical school model. The 26-items developed questionnaire, grouped into seven scales, showed excellent reliability and validity.

\section{COMPETING INTERESTS}

The authors declare that there are no competing interests related to this study.

\section{ACKNOWLEDGEMENT}

This study received funding and was supported by the Ministry of Research, Technology, and Higher Education of Indonesia.

\section{SUPPLEMENTARY MATERIALS}

The 'Role Model Sehat' questionnaire is available upon request to the authors or JPKI's editorial board.

\section{REFERENCES}

1. Asean University Network-Health Promotion Network. AUN healthy university framework. 2nd ed. 2017 Available from: http://www. aunsec.org/photo2019-1/2019-8-20-HUF.pdf. Accessed November 28, 2019.

2. Dooris M. The "health promoting university": a critical exploration of theory and practice. Health Educ J. 2001; 101(2):51-60. doi: 10.1108/09654280110384108

3. Leman MA, Claramita M, Rahayu GR. Defining a 'healthy role-model' for medical schools: learning components that count. JMDH 2020;13:1325-35. doi: https://doi.org/10.2147/ JMDH.S279574.

4. Online Archieve of WMA Declaration Of Geneva. 2017 [Internet]. World Medical Association. Available from: https://www. wma.net/policies-post/wma-declaration-ofgeneva $/$ \&pdfName=wma-declaration-of-geneva. Accessed March 27, 2019.

5. McAleer S, Roff S. Educational environment. In: Dent JA, Harden RM, editors. A practical guide for medical teachers. 4th ed. London: Elsevier; 2013; pp. 392-9.

6. Paice E, Heard S, Moos F. How important are role-model in making good doctors? BMJ 2002;325:707-10. doi: 10.1136/ bmj.325.7366.707.

7. Kenny NP, Mann KV, MacLeod H. Rolemodelling in physicians' professional formation: reconsidering an essential but untapped educational strategy. Acad Med, 2003;78(12):1203-10. doi: 10.1097/00001888. 200312000-00002

8. Stern DT, Papadakis M. The developing physician-becoming a professional. N Engl J Med, 2006;355:1794-9. doi: 10.1056/NEJMra054783.

9. Cruess SR, Cruess RL, Steinert Y. Rolemodelling-making the most of a powerful teaching strategy. BMJ 2008;336:718-21. doi: 10.1136/bmj.39503.757847.BE

10. Kahn MW. Etiquette-based medicine. N Engl J Med, 2008;358(19):1988-9. doi: 10.1056/ NEJMp0801863.

11. Ware JE. Standards for validating health measures: definition and content. J Chron Dis. 1987;40(6):473-80. doi: 10.1016/00219681(87)90003-8.

12. Artino AR, La Rochelle JS, Dezee KJ, Gelhbach $H$. Developing questionnaires for educational research:AMEEguide No. 87. Med Teach, 2014;36: 463-74. doi: 10.3109/0142159X.2014.889814.

13. Lawshe $\mathrm{CH}$. A quantitative approach to content validity. Pers. Psychol, 1975;28: 563-75. doi: 10.1111/j.1744-6570.1975.tb01393.x. 
14. Tourangeau R, Rips LJ, Rasinski KA. The psychology of survey response. New York: Cambridge University Press; 2000.

15. Karabenick SA, Woolley ME, Friedel JM, Ammon BV, Blazevski J, Bonney CR, De Groot E, Gilbert MC, Musu L, Kempler TM, Kelly KL. Cognitive processing of self-report items in educational research: Do they think what we mean? Educ Psychol, 2007;42(3):139-51. doi: $10.1080 / 00461520701416231$

16. Willis GB. Cognitive interviewing: A tool for improving questionnaire design. Thousand Oaks, CA: Sage Publications; 2005.

17. Watt T, Rasmussen AK, Groenvold M, Bjorner JB, Watt SH, Bonnema SJ, Hegedus L, FeldtRasmussen U. Improving a newly developed patient-reported outcome for thyroid patients, using cognitive interviewing. Quality of Life Research. 2008;17:1009-17. doi: 10.1007/ s11136-008-9364-z.

18. Willis GB, Artino AR. What do our respondents think we're asking? Using cognitive interviewing to improve medical education surveys. J Grad Med Educ. 2013;5(3):353-6. doi: 10.4300/ JGME-D-13-00154.1.

19. Hair JF, Sarstedt M, Ringle CM, Gudergan SP. Advanced Issues in Partial Least Squares Structural Equation Modeling (PLS-SEM). Sage, Thousand Oaks, CA; 2018.

20. Hair JF, Hult GTM, Ringle CM, Sarstedt M. A primer on partial least squares structural equation modeling (PLS-SEM). 2 ed. Sage, Thousand Oaks, CA; 2017a.

21. Ringle CM, Sarstedt M, Schlittgen R, Taylor CR. PLS path modeling and evolutionary segmentation. Journal of Business Research, 2013; 66: 1318-24. doi: 10.1016/j.jbusres.2012.02.031
22. Hair JF, Sarstedt M, Hopkins L, Kupperlwieser VG. (2014) Partial least squares structural equation modeling (PLS-SEM): An emerging tool in business research", European Business Review, 2014;26(2):106-21. doi: 10.1108/EBR-102013-0128.

23. Hair JF, Ringle CM, Sarstedt M. PLS-SEM: Indeed a silver bullet. Journal of Marketing Theory and Practice, 2011;19:139-51. doi: 10.2753/ MTP1069-6679190202.

24. Hulland J. Use of partial least squares (PLS) in strategic management research: A review of four recent studies. Strategic Management Journal, 1999;20:195-204. doi: 10.1002/(SICI)10970266(199902)20:23.0.CO;2-7.

25. Henseler J, Ringle CM, Sarstedt M. A new criterion for assessing discriminant validity in variance-based structural equation modeling. Journal of the Academy of Marketing Science, 2015;43:115-35

26. Becker JM, Klein K, Wetzels M. Formative hierarchical latent variable models in PLS-SEM: Recommendations and guidelines. Long Range Planning, 2012;45: 359-94. doi: 10.1016/j. $\operatorname{lrp} .2012 .10 .001$

27. Chin WW, Marcolin BL, Newsted PR. A partial least squares latent variable modeling approach for measuring interaction effects: Results from a Monte Carlo simulation study and an electronicmail emotion/adoption study. Information Systems Research, 2003;14:189-217. doi: $10.1287 /$ isre.14.2.189.16018.

28. Ringle CM, Sarstedt M, Straub DW. A critical look at the use of PLS-SEM in MIS Quarterly. MIS Quarterly, 2012;36: iii-xiv. doi: $10.2307 / 41410402$. 